\title{
Efficacy and safety of QVA I49 compared to the concurrent administration of its monocomponents indacaterol and glycopyrronium: the BEACON study
}

\author{
This article was published in the following Dove Press journal: \\ International Journal of COPD \\ 16 October 2013 \\ Number of times this article has been viewed
}

\author{
Ronald Dahl' \\ Dalal Jadayel ${ }^{2}$ \\ Vijay KT Alagappan ${ }^{3}$ \\ Hungta Chen ${ }^{3}$ \\ Donald Banerji ${ }^{3}$
}

'Department of Dermatology, Allergy Centre, Odense University Hospital, Odense, Denmark; ${ }^{2}$ Novartis Horsham Research Centre, Horsham, UK; ${ }^{3}$ Novartis Pharmaceuticals Corporation, East Hanover, NJ, USA
Correspondence: Ronald Dahl Department of Dermatology, Allergy Centre, Odense University Hospital, Sdr Boulevard 29, 5000 Odense C, Denmark Tel +45654l3620

Email ronadahl@rm.dk
Introduction: The BEACON study evaluated the efficacy and safety of QVA149, a once-daily dual bronchodilator containing a fixed-dose combination of the long-acting $\beta_{2}$-agonist (LABA) indacaterol and long-acting muscarinic antagonist (LAMA) glycopyrronium (NVA237), in development for the treatment of patients with chronic obstructive pulmonary disease (COPD), compared with the free-dose concurrent administration of indacaterol plus glycopyrronium (IND+GLY).

Methods: In this multicenter, double-blind, parallel group study, patients with stage II or stage III COPD (Global initiative for chronic Obstructive Lung Disease [GOLD] 2010) were randomized (1:1) to once-daily QVA149 (110 $\mu \mathrm{g}$ indacaterol/50 $\mu \mathrm{g}$ glycopyrronium) or concurrent administration of indacaterol $(150 \mu \mathrm{g})$ and glycopyrronium $(50 \mu \mathrm{g})$ via the Breezhaler ${ }^{\mathbb{B}}$ device (Novartis AG, Basel, Switzerland) for 4 weeks. The primary endpoint was to evaluate the noninferiority of QVA149 as compared with concurrent administration of IND+GLY, for trough forced expiratory volume in 1 second $\left(\mathrm{FEV}_{1}\right)$ after 4 weeks of treatment. The other assessments included $\mathrm{FEV}_{1}$ area under the curve from 0 to 4 hours $\left(\mathrm{AUC}_{0-4 \text { hours }}\right)$ at day 1 and week 4 , symptom scores, rescue medication use, safety, and tolerability over the 4-week study period.

Results: Of 193 patients randomized, 187 (96.9\%) completed the study. Trough FEV at week 4 for QVA149 and IND+GLY was $1.46 \mathrm{~L} \pm 0.02$ and $1.46 \mathrm{~L} \pm 0.18$, respectively. The FEV $\mathrm{AUC}_{0-4 \text { hours }}$ at day 1 and week 4 were similar between the two treatment groups. Both treatment groups had a similar reduction in symptom scores and rescue medication use for the 4-week treatment period. Overall, 25.6\% of patients in QVA149 group and 25.2\% in the IND+GLY group experienced an adverse event, with the majority being mild-to-moderate in severity. No deaths were reported during the study or during the 30 days follow-up period.

Conclusion: The BEACON study demonstrated that once-daily QVA149 provides an efficacy and safety profile similar to the concurrent administration of its monocomponents indacaterol and glycopyrronium.

Keywords: COPD, LABA, LAMA, $\mathrm{FEV}_{1} \mathrm{AUC}_{0-4 \text { hours }}$, rescue medication

\section{Introduction}

Current guidelines for the effective management of moderate-to-severe chronic obstructive pulmonary disease (COPD) recommend the addition of a second longacting bronchodilator class to the existing bronchodilator regimen, thus combining a long-acting $\beta_{2}$-agonist (LABA) with a long-acting muscarinic antagonist (LAMA). ${ }^{1}$ Moreover, $\beta_{2}$-agonists and muscarinic antagonists have a complementary mechanism 
of action, and their combination has been shown to improve bronchodilation as compared with their respective monotherapies. ${ }^{2-8}$

The addition of a second bronchodilator has been seen to provide additional benefits in terms of enhanced bronchodilation, inspiratory capacity, improved dyspnea, quality of life, and a decline in rescue medication use. ${ }^{3,9}$ This concept of dual bronchodilation can currently be achieved with a free combination of a LABA and LAMA. However, the free LABA/LAMA combination requires the administration of the medications separately in different devices, and this would potentially affect patient convenience and compliance. ${ }^{10}$ Thus, a fixed-dose LABA/LAMA combination would be a better treatment option.

Currently, there is no fixed-dose combination of LABA/ LAMA available for patients with COPD. QVA149, in development for the treatment of patients with COPD, is a once-daily dual bronchodilator containing a fixed-dose combination of the LABA indacaterol and the LAMA glycopyrronium (NVA237). Both indacaterol and glycopyrronium have established safety and efficacy profiles, ${ }^{11-16}$ and are approved as once-daily monotherapies for the maintenance treatment of COPD. In addition, they both offer the benefit of being administered in the same Breezhaler ${ }^{\circledR}$ device (Novartis AG, Basel, Switzerland). Previous Phase III studies have demonstrated that QVA149 is safe and provides superior and clinically meaningful improvements in lung function compared with its monocomponents indacaterol $150 \mu \mathrm{g}$ and glycopyrronium $50 \mu \mathrm{g}$, as well as tiotropium $18 \mu \mathrm{g}$ and salmeterol/fluticasone 50/500 $\mu \mathrm{g}$. These improvements in lung function were translated into concomitant improvements in patient-reported outcomes (health status via St George's Respiratory Questionnaire [SGRQ] and breathlessness via transition dyspnea index [TDI]) and a reduction in exacerbations. ${ }^{17-21}$ QVA149 is thus expected to provide similar efficacy and safety as compared with the concurrent administration of its monocomponents.

In addition, the fixed-dose combination will offer a simplified and more convenient dosing regimen, compared with a free combination with the potential to improve patient compliance.

In the BEACON study, the efficacy and safety of oncedaily QVA149 was evaluated in comparison with the concurrent administration of its monocomponents - indacaterol and glycopyrronium - over a treatment period of 4 weeks.

\section{Methods}

\section{Study design and treatment}

This was a multicenter, double-blind, parallel-group, activecontrolled, noninferiority design to compare the efficacy of QVA149 110/50 $\mu \mathrm{g}$ versus concurrent administration of its monocomponents indacaterol $(150 \mu \mathrm{g})$ and glycopyrronium $(50 \mu \mathrm{g})$ in patients with moderate-to-severe COPD (Figure 1). ${ }^{22}$ The study consisted of a prerandomization period, which included screening/washout (7 days) and run-in period (14 days). To stabilize patients and standardize baseline lung function, open-label, $150 \mu \mathrm{g}$ of indacaterol and $50 \mu \mathrm{g}$ of glycopyrronium were administered during the 14-day run-in period. Patients were then randomized (1:1) to QVA149 and placebo or concurrent administration of indacaterol (IND) plus (+) glycopyrronium (GLY); all were administered via the Breezhaler ${ }^{\circledR}$ device.

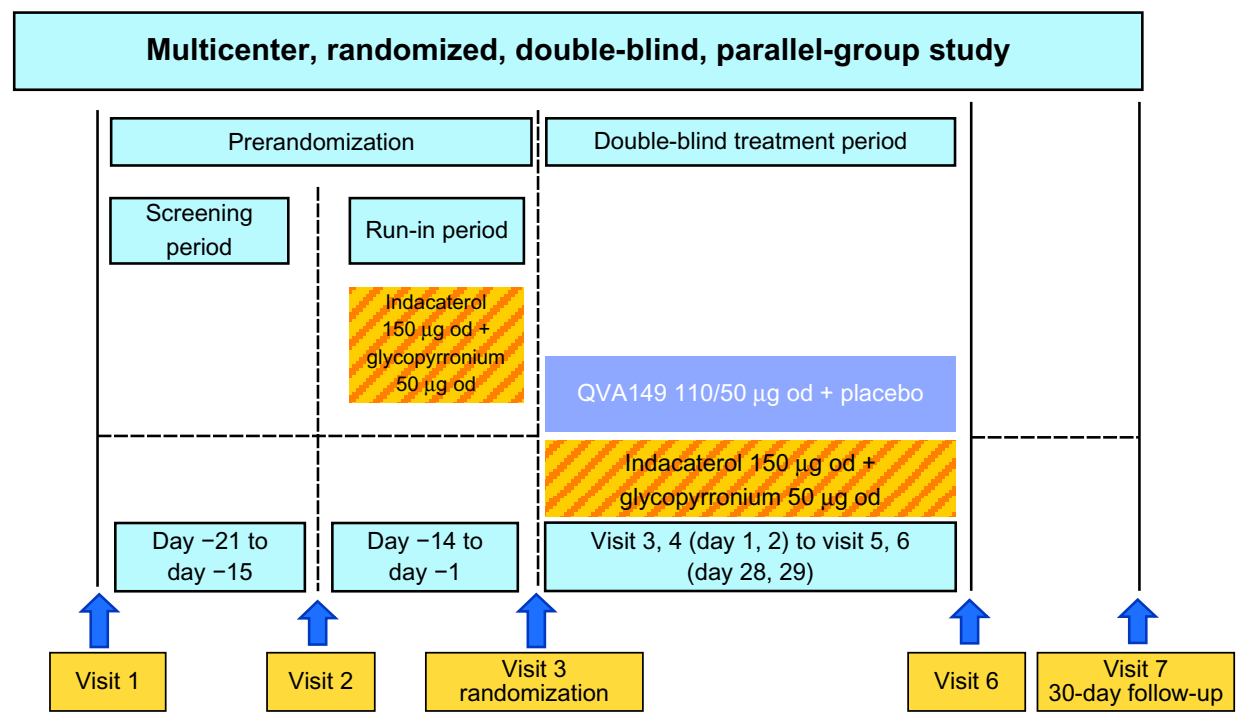

Figure I BEACON study design.

Abbreviation: od, once daily. 
To ensure that the fine-particle dose of indacaterol delivered to the lung from QVA149 matched that of the monotherapy, the dose of indacaterol was reduced from $150 \mu \mathrm{g}$ to $110 \mu \mathrm{g}$ when given in the QVA149 fixed-dose combination. Pharmacokinetic data from previous indacaterol studies demonstrated the similarity of the steady-state systemic exposures of $150 \mu \mathrm{g}$ of indacaterol and $50 \mu \mathrm{g}$ of glycopyrronium to QVA149 (110/50 $\mu \mathrm{g})$. Patients took their study medication (two capsules) concurrently, once daily, between 8-11 am.

Salbutamol (albuterol) was allowed as rescue medication. Inhaled corticosteroids (ICS) were allowed if the patients were on the stable ICS dose for at least 30 days prior to visit 1 and during the study. The protocol and procedures were approved by relevant institutional review boards and ethics committees. All participants provided written informed consent, and the study was designed in accordance with the International Conference on Harmonisation (ICH) Harmonised Tripartite Guidelines for Good Clinical Practice and with the ethical principles of the World Medical Association's Declaration of Helsinki.

\section{Patients}

According to the Global initiative for chronic Obstructive Lung Disease (GOLD) 2010 guidelines, men and women were enrolled if they: were $\geq 40$ years of age with moderateto-severe COPD (stage II or stage III); had post-bronchodilator forced expiratory volume in 1 second $\left(\mathrm{FEV}_{1}\right) \geq 30 \%$ and $<80 \%$ of the predicted normal; post-bronchodilator $\mathrm{FEV}_{1} /$ forced vital capacity $(\mathrm{FVC})<0.70$; were current or ex-smokers, having a smoking history of at least ten packyears. In addition, all patients enrolled were symptomatic (coughing, wheezing, sputum production, breathlessness) according to daily electronic diary data, with a total symptom score of 1 or more (on a scale of 0 to 3 ) on at least 3 days prior to visit 3 .

Key exclusion criteria included: patients with type I or uncontrolled type II diabetes; history of long QT syndrome or prolonged QTc; patients who had a COPD exacerbation that required treatment with antibiotics and/or oral corticosteroids and/or hospitalization in the 6 weeks prior to visit 1 ; patients who had a respiratory tract infection within 4 weeks prior to visit 1 ; and patients who had a clinically significant electrocardiogram abnormality.

\section{End points and assessments}

The primary endpoint was to evaluate the noninferiority of QVA149 compared to concurrent administration of indacaterol plus glycopyrronium for trough $\mathrm{FEV}_{1}$ (mean of
23 hours, 15 minutes and 23 hours, 45 minutes postdose) after 4 weeks of treatment in patients with moderate-to-severe COPD. The other assessments included $\mathrm{FEV}_{1} \mathrm{AUC}_{0-4 \text { hours }}$ at day 1 and week 4 , daily number of puffs of rescue medication use, e-diary data with recording of daily clinical symptoms on the scale of $0-3$ (where 0 refers to no symptoms) over the study period of 4 weeks, and safety and tolerability (adverse events, laboratory tests, electrocardiograms, and vital signs).

\section{Statistical method and analysis}

The treatment difference between QVA149 and concurrent administration of indacaterol and glycopyrronium for trough $\mathrm{FEV}_{1}$ was estimated to be $0 \mathrm{~mL}$ after 4 weeks of treatment. Based on the treatment difference of $226 \mathrm{~mL}$ between QVA149 300/50 $\mu \mathrm{g}$ and placebo (lower limit of the $95 \%$ confidence interval $[\mathrm{CI}]$ of $192 \mathrm{~mL}$ ) in mean trough $\mathrm{FEV}_{1}$ in the QVA149A2204 study, ${ }^{23}$ the noninferiority margin of $100 \mathrm{~mL}$ was taken to be approximately one-half of this. Noninferiority was considered to be achieved if the lower bound values of two-sided $95 \%$ CI were greater than $-100 \mathrm{~mL}$.

A total of 154 evaluable patients would achieve $90 \%$ power with a one-sided noninferiority test at a significance level of $2.5 \%$. Approximately 184 randomized patients were required to adjust for an estimated combined attrition rate of $17 \%$. The per protocol set was the primary analysis data set for this noninferiority study and included all patients in the full analysis set without any major protocol deviations.

The primary analysis was performed using a mixed model, with treatment as a fixed effect. Trough $\mathrm{FEV}_{1}$ measurement at baseline and $\mathrm{FEV}_{1}$ measurement prior and post to inhalation of short-acting bronchodilator were taken as covariates. This model also included smoking status (current/ex-smoker), history of inhaled corticosteroids at baseline as fixed effects, and center as random effects. Secondary analyses in terms of $\mathrm{FEV}_{1} \mathrm{AUC}_{0-4 \text { hours }}$ at day 1 and week 4 , daily number of puffs of rescue medication, and diary symptoms were performed using a similar mixed model (as per the primary endpoint) with the associated $95 \%$ CI. Secondary analyses were not statistically adjusted for multiplicity.

The safety set included all patients who received at least one dose of the study drug. The number (\%) of patients with notable values of pulse rate of $<40$ and $>90 \mathrm{bpm}$, systolic blood pressure of $<90$ and $>140 \mathrm{mmHg}$, and diastolic blood pressure of $<50$ and $>90 \mathrm{mmHg}$ was summarized. Notable QTe values and changes from baseline were summarized. A notable value was defined as a QTc interval of greater than 450 milliseconds for both sexes at baseline and the number 


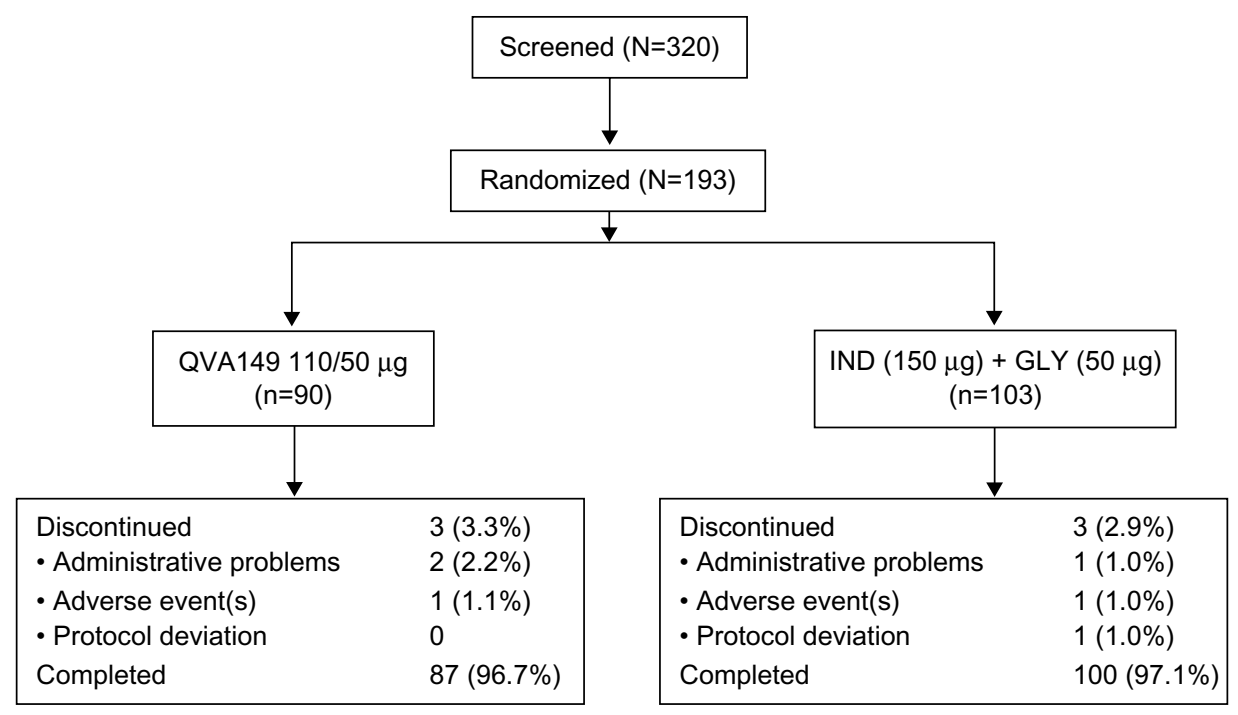

Figure 2 Patient disposition.

Abbreviation: IND+GLY, indacaterol and glycopyrronium.

of newly occurring or worsening notable QTc values for postbaseline time points.

\section{Results}

\section{Patients}

Of the total 320 patients screened, 193 were randomized and 187 (96.9\%) completed the study (QVA149:
$\mathrm{N}=87$, IND+GLY: N=100) (Figure 2). The patient demographics and baseline characteristics were numerically comparable between the two treatment groups (Table 1).

\section{Efficacy}

Patients who were stable on the concurrent administration of indacaterol and glycopyrronium during the run-in period

Table I Demographics and clinical characteristics of patients at baseline

\begin{tabular}{|c|c|c|c|}
\hline & $\begin{array}{l}\text { QVAI } 49(1 \text { I } 0 / 50 \mu g) \\
N=90\end{array}$ & $\begin{array}{l}\text { IND }(150 \mu \mathrm{g})+\mathrm{GLY}(50 \mu \mathrm{g}) \\
\mathrm{N}=103\end{array}$ & $\begin{array}{l}\text { Total } \\
N=193\end{array}$ \\
\hline Age (years) & $65.6(7.28)$ & $64.2(7.40)$ & $64.9(7.36)$ \\
\hline \multicolumn{4}{|l|}{ Sex, n (\%) } \\
\hline Male & $58(64.4)$ & $59(57.3)$ & $117(60.6)$ \\
\hline Female & $32(35.6)$ & $44(42.7)$ & $76(39.4)$ \\
\hline \multicolumn{4}{|l|}{ Race, n (\%) } \\
\hline Caucasian & $90(100)$ & $103(100)$ & $193(100)$ \\
\hline Pre-bronchodilator FEV (\% predicted) & $45.1(12.88)$ & $44.4(12.95)$ & 44.7 ( 12.89$)$ \\
\hline Post-bronchodilator FEV (\% predicted) & $54.1(12.27)$ & $53.8(12.85)$ & $54.0(12.55)$ \\
\hline FEV, reversibility (\% increase) & $22.7(16.78)$ & $24.4(19.47)$ & $23.6(18.24)$ \\
\hline Duration of COPD (years) & $7.3(5.03)$ & $6.8(4.83)$ & $7.0(4.92)$ \\
\hline \multicolumn{4}{|l|}{ Severity of COPD (GOLD 20I0), n (\%) } \\
\hline Moderate & $55(6 I . I)$ & $60(58.3)$ & $115(59.6)$ \\
\hline Severe & $35(38.9)$ & $43(4 \mid .7)$ & $78(40.4)$ \\
\hline \multicolumn{4}{|l|}{ ICS use, n (\%) } \\
\hline No & $29(32.2)$ & $39(37.9)$ & $68(35.2)$ \\
\hline Yes & $61(67.8)$ & $64(62.1)$ & $125(64.8)$ \\
\hline \multicolumn{4}{|l|}{ Smoking history, n (\%) } \\
\hline Ex-smoker & $53(58.9)$ & $62(60.2)$ & 115 (59.6) \\
\hline Current smoker & $37(4 I .1)$ & $41(39.8)$ & $78(40.4)$ \\
\hline Number of pack-years & $41.6(17.84)$ & $39.2(20.22)$ & $40.3(19.14)$ \\
\hline
\end{tabular}


continued to be stable when randomized to receive QVA149 along with the free-dose concurrent administration of indacaterol and glycopyrronium, with similar maintenance of their lung function from day 1 to week 4 without any significant difference. The least squares mean \pm standard error $\left(\mathrm{LSM} \pm \mathrm{SE}\right.$ ) trough $\mathrm{FEV}_{1}$ at week 4 for QVA149 and for the free-dose combination of IND+GLY was $1.5 \mathrm{~L} \pm 0.02$ and $1.5 \mathrm{~L} \pm 0.18$, respectively (Figure 3 ).

The FEV ${ }_{1} \mathrm{AUC}_{0-4 \text { hours }}$ at day 1 and week 4 were similar for QVA149 in comparison with IND+GLY (Figure 4). Also, the $\mathrm{FEV}_{1} 5$ minutes to 4 hours postdose spirometry measurements at week 4 were similar between the two groups (Figure 5). Likewise, both groups had a similar reduction in symptom scores and rescue medication use from baseline for more than 4 weeks of treatment (Table 2).

The overall incidence of adverse events (AEs) was similar in both treatment groups, with $25.6 \%$ of patients experiencing an AE in the QVA149 group and $25.2 \%$ in the IND+GLY treatment group, with the majority of AEs being mild-to-moderate in severity. Nasopharyngitis and COPD worsening were the most frequently occurring AEs in both treatment groups (Table 3).

A similar number of patients had serious AEs in the IND+GLY treatment group (5.8\%) compared with QVA149 group (4.4\%). No patient discontinued the study medication due to a serious adverse event (SAE). There were no cardio- and cerebrovascular SAEs in either treatment group.

Four patients in the IND+GLY group had notably increased QTc levels, compared with one patient in the QVA149 treatment group (Table 4). A total of six patients $(6.7 \%)$ in the QVA149 group had AEs that were suspected to

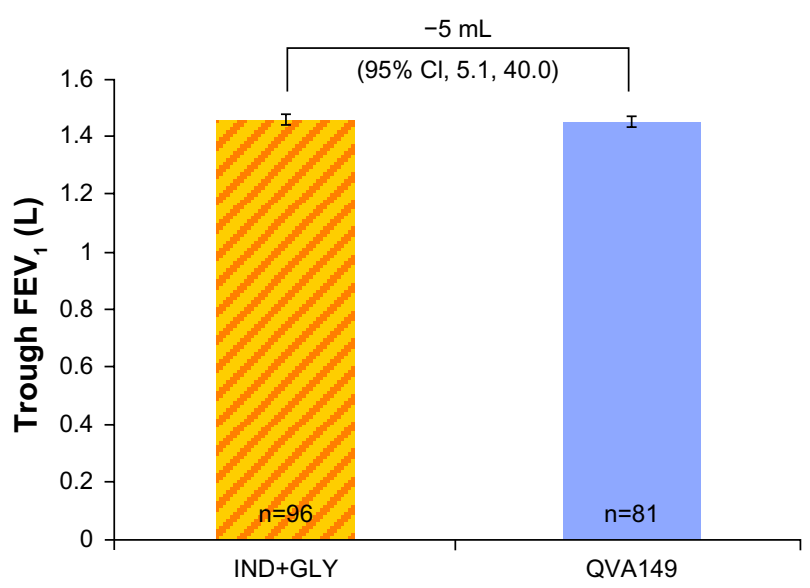

Figure 3 Trough FEV, (L) at week 4.

Abbreviations: IND+GLY, indacaterol and glycopyrronium; $\mathrm{FEV}_{\mathrm{l}}$, forced expiratory volume in I second; $\mathrm{Cl}$, confidence interval.

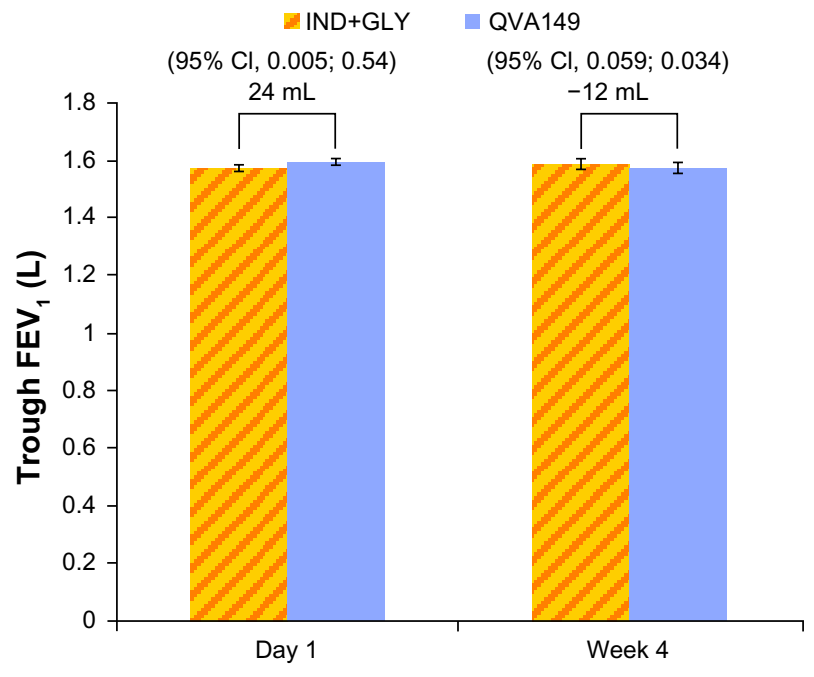

Figure $4 \mathrm{FEV}, \mathrm{AUC}_{0-4 \text { hours }}$ at day I and week 4.

Abbreviations: $\mathrm{FEV}_{1}$, forced expiratory volume in I second; $\mathrm{AUC}$, area under curve; IND+GLY, indacaterol and glycopyrronium; $\mathrm{Cl}$, confidence interval.

be study drug-related, compared with two patients (1.9\%) in the indacaterol and glycopyrronium group. No deaths were reported in either treatment group during the study or during the 30-day follow-up period.

\section{Discussion}

The BEACON study directly compared the efficacy and safety of the fixed and the free combination of a LABA with a LAMA. The study met its primary objective to prove QVA149 as noninferior to the concurrent administration of indacaterol and glycopyrronium for its effect on trough FEV $_{1}$ after 4 weeks of treatment. QVA149 also improved other clinical endpoints and had a safety and tolerability

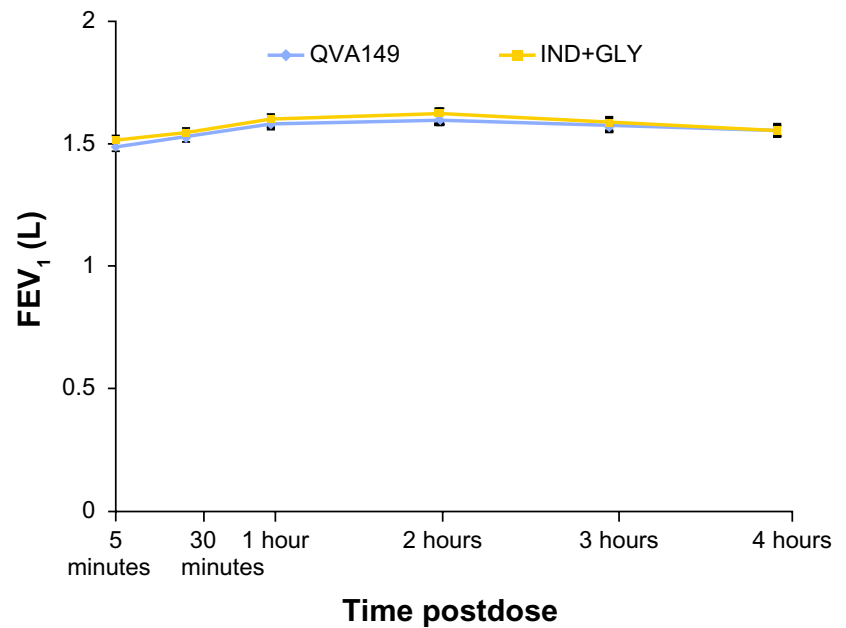

Figure $5 \mathrm{FEV}$, for the first 4 hours at week 4.

Abbreviations: IND+GLY, indacaterol and glycopyrronium; $\mathrm{FEV}_{1}$, forced expiratory volume in I second. 
Table 2 Daily total symptom score and rescue medication use over 4 weeks

\begin{tabular}{|c|c|c|c|c|c|c|c|c|}
\hline \multirow[t]{2}{*}{ Treatment } & \multirow[t]{2}{*}{ n } & \multirow{2}{*}{$\begin{array}{l}\text { Baseline } \\
\text { mean (SE) }\end{array}$} & \multirow[t]{2}{*}{ LS mean } & \multirow[t]{2}{*}{ SE } & \multirow[t]{2}{*}{ Comparison } & \multicolumn{3}{|c|}{ Treatment difference } \\
\hline & & & & & & LS mean & SE & $95 \% \mathrm{Cl}$ \\
\hline \multicolumn{9}{|c|}{ Change from baseline in the daily total symptom score } \\
\hline QVAI49 (II0/50 $\mu \mathrm{g})(\mathrm{N}=84)$ & 84 & $5.25(0.275)$ & -0.42 & 0.140 & \multirow{2}{*}{$\begin{array}{l}\text { QVAI49- } \\
\text { (IND+GLY) }\end{array}$} & \multirow[t]{2}{*}{0.07} & \multirow[t]{2}{*}{0.161} & \multirow[t]{2}{*}{$(-0.24,0.39)$} \\
\hline IND $(I 50 \mu g)+$ GLY $(50 \mu g)(N=97)$ & 95 & $5.74(0.295)$ & -0.49 & 0.130 & & & & \\
\hline \multicolumn{9}{|c|}{ Change from baseline in the mean daily number of puffs of rescue medication } \\
\hline QVAI49 (II0/50 $\mu \mathrm{g})(\mathrm{N}=84)$ & 84 & $2.24(0.266)$ & -0.45 & 0.124 & \multirow{2}{*}{$\begin{array}{l}\text { QVAI49- } \\
\text { (IND+GLY) }\end{array}$} & \multirow[t]{2}{*}{-0.04} & \multirow[t]{2}{*}{0.159} & \multirow[t]{2}{*}{$(-0.35,0.28)$} \\
\hline IND $(I 50 \mu g)+$ GLY $(50 \mu g)(N=97)$ & 95 & $2.04(0.265)$ & -0.42 & 0.113 & & & & \\
\hline
\end{tabular}

Abbreviations: IND+GLY, indacaterol and glycopyrronium; LS mean, least squares mean; SE, standard error; $\mathrm{Cl}$, confidence interval.

profile that was similar to the concurrent administration of its monocomponents indacaterol and glycopyrronium.

There have been studies demonstrating the combination of different classes of bronchodilators to improve efficacy without compromising safety in patients whose symptoms are not adequately controlled by bronchodilator monotherapy. ${ }^{3,6,724}$ This is due to the fact that LABAs and LAMAs are known to have a complementary mode of action, especially in terms of bronchodilation. LABAs augment the bronchodilatory effect produced by LAMAs by decreasing the release of acetylcholine via modulation of cholinergic neurotransmission. Moreover, LAMAs antagonize the effects of acetylcholine, amplifying the bronchodilation caused by LABAs. It has also been observed in previous studies that concurrent administration of a LABA with a LAMA produces superior bronchodilation in comparison with

Table 3 Most frequent AEs (at least I\% in any treatment group) by preferred term of patients

\begin{tabular}{|c|c|c|}
\hline & $\begin{array}{l}\text { QVAI49 } \\
(110 / 50 \mu \mathrm{g}) \\
\mathrm{N}=90 \\
\mathrm{n}(\%)\end{array}$ & $\begin{array}{l}\text { IND }(150 \mu \mathrm{g})+ \\
\text { GLY }(50 \mu \mathrm{g}) \\
\mathbf{N}=103 \\
\mathrm{n}(\%)\end{array}$ \\
\hline Patients with any $\mathrm{AE}(\mathrm{s})$ & $23(25.6)$ & $26(25.2)$ \\
\hline \multicolumn{3}{|l|}{ Preferred term } \\
\hline Nasopharyngitis & $7(7.8)$ & $6(5.8)$ \\
\hline COPD worsening & $4(4.4)$ & $2(1.9)$ \\
\hline Cough & $4(4.4)$ & $2(1.9)$ \\
\hline Chest discomfort & $2(2.2)$ & 0 \\
\hline Influenza & $2(2.2)$ & I (I.0) \\
\hline Myalgia & $2(2.2)$ & 0 \\
\hline Pneumonia & $2(2.2)$ & 0 \\
\hline Aortic aneurysm & $\mathrm{I}(\mathrm{I} . \mathrm{I})$ & 0 \\
\hline Breast pain & $\mathrm{I}(\mathrm{I} . \mathrm{I})$ & 0 \\
\hline Depression & $\mathrm{I}(\mathrm{I} . \mathrm{I})$ & 0 \\
\hline Diarrhea & $\mathrm{I}(\mathrm{I} . \mathrm{I})$ & $\mathrm{I}(\mathrm{I} .0)$ \\
\hline Dysphonia & $\mathrm{I}(\mathrm{I} . \mathrm{I})$ & $\mathrm{I}(\mathrm{I} .0)$ \\
\hline Dyspnea & $\mathrm{I}(\mathrm{I} . \mathrm{I})$ & $2(1.9)$ \\
\hline Headache & $\mathrm{I}(\mathrm{I} . \mathrm{I})$ & $\mathrm{I}(\mathrm{I} .0)$ \\
\hline Ligament injury & $\mathrm{I}(\mathrm{I} . \mathrm{I})$ & 0 \\
\hline
\end{tabular}

Abbreviations: IND+GLY, indacaterol and glycopyrronium; AEs, adverse events; COPD, chronic obstructive pulmonary disease. the monotherapies, with additional benefits of reductions in dyspnea, dynamic hyperinflation, improved symptoms, and exercise endurance. QVA149 has been found to be efficacious and well-tolerated in comparison with indacaterol, glycopyrronium, tiotropium, salmeterol/fluticasone, and placebo in previous Phase III clinical trials. ${ }^{4,7,25}$ In the present study, QVA149 provided similar efficacy in terms of trough $\mathrm{FEV}_{1}$ and $\mathrm{FEV}_{1} \mathrm{AUC}_{0-4 \text { hours }}$ as compared with IND+GLY, along with providing the advantage of dual bronchodilation in a single inhaler device. Also, peak $\mathrm{FEV}_{1}$ values revealed that the maximum improvements seen with the lung function were similar in both treatment groups. The symptomatic improvements achieved by patients in the QVA149 treatment group reinforced the association between improvements in lung function with other clinical outcomes, ${ }^{5,26}$

ICS are recommended for patients with severe COPD and recurrent exacerbations. However, in the real world setting, patients with COPD are often inappropriately treated with ICS in combination with a LABA, irrespective of their GOLD classification. ${ }^{27}$ In the present study, $65 \%$ of the study population ( $60 \%$ had moderate and $40 \%$ had severe COPD) were on ICS at baseline. The BEACON study targeted this segment of patients with moderate-to-severe COPD for achieving more effective bronchodilation, symptom control,

Table 4 Number (\%) of patients with newly occurring or worsening notable QTc values (according to Fridericia's formula) and maximum increase from baseline on study treatment

\begin{tabular}{|c|c|c|}
\hline According to & QVAI49 & IND $(150 \mu g)+$ \\
\hline \multirow[t]{3}{*}{ Fridericia's formula } & $(1 / 0 / 50 \mu g)$ & GLY $(50 \mu \mathrm{g})$ \\
\hline & $\mathbf{N}=90$ & $\mathbf{N}=103$ \\
\hline & $\mathrm{n} / \mathbf{N}(\%)$ & $n / N(\%)$ \\
\hline $\mathrm{QTc}>450 \mathrm{~ms}$ & $1 / 89(1.1)$ & $4 / 102(3.9)$ \\
\hline $\mathrm{QTc}>480 \mathrm{~ms}$ & $0 / 89$ & $0 / 102$ \\
\hline $\mathrm{QTc}>500 \mathrm{~ms}$ & $0 / 89$ & $0 / 102$ \\
\hline \multicolumn{3}{|c|}{ Maximum increase from baseline } \\
\hline $30-60 \mathrm{~ms}$ & $0 / 84$ & $4 / 101(4.0)$ \\
\hline$>60 \mathrm{~ms}$ & $0 / 84$ & $0 / 101$ \\
\hline
\end{tabular}

Abbreviations: IND+GLY, indacaterol and glycopyrronium; ms, milliseconds. 
and reduced requirements for rescue medication with a fixeddose LABA/LAMA combination.

Although safety was not a primary objective of the study, it was important to demonstrate that there was no difference in the safety profile between the fixed-dose combination QVA149 and the free combination therapy with indacaterol plus glycopyrronium. Overall, the incidence of AEs reported was numerically similar in both of the treatment groups, with no additional safety concerns for either the fixed- or free-dose combination. The results were consistent with the previous clinical studies that assessed the cardiac safety of QVA149, ${ }^{17-20,28}$ confirming that no significant cardiovascular safety concerns were observed with QVA149.

Patients with COPD have several comorbidities and are likely to be on other medications. ${ }^{29}$ Also, physical deconditioning due to hyperinflation and cognitive impairment would make the use of multiple inhalers difficult for these patients. ${ }^{10}$ In comparison to the free-dose combinations, QVA149 provides the advantage of delivering the LABA/ LAMA combination in a single inhaler device, and thus aims to simplify the treatment regimen, improving patient adherence. $^{10}$

\section{Conclusion}

The BEACON study demonstrated that once-daily QVA149 improves lung function and symptom scores, reduces rescue medication use, and has a safety and tolerability profile similar to the free combination of its monocomponents ie, indacaterol and glycopyrronium. This study provides reassurance that the LABA/LAMA fixed-dose combination QVA149 provides benefits of dual bronchodilation in a single device, making it a more convenient treatment option for patients with COPD.

\section{Acknowledgments}

The authors thank the patients who participated and the staff at the participating clinical centers. The study was funded by Novartis Pharma AG, Basel, Switzerland. The authors were assisted in the preparation of the manuscript by Mohit Joshi and Mark J Fedele (Novartis).

\section{Disclosure}

In the past 3 years, Professor Dahl has received compensation for consulting with Boehringer Ingelheim, Novartis, Vectura, Roche, Elevation Pharmaceuticals, Inc, and Norpharma. He has also undertaken research funded by AstraZeneca, Boehringer Ingelheim, Chiesi, GlaxoSmithKline, Novartis,
ALK-Abello, and Stallergenes and has participated in educational activities sponsored by AstraZeneca, Boehringer Ingelheim, GlaxoSmithKline, ALK-Abello, Novartis, and Almirall. Dalal Jadayel, Vijay KT Alagappan, Hungta Chen, and Donald Banerji are employees of Novartis. The authors report no other conflicts of interest in this work.

\section{References}

1. Global initiative for chronic Obstructive Lung Disease (GOLD). Global Strategy for the Diagnosis, Management, and Prevention of Chronic Obstructive Pulmonary Disease. 2010 update. Global Initiative for Chronic Obstructive Lung Disease, Inc; 2010. Available from: http:// www.goldcopd.org/uploads/users/files/GOLDReport_April112011.pdf. Accessed on July 20, 2012.

2. Karner C, Cates CJ. Long-acting beta(2)-agonist in addition to tiotropium versus either tiotropium or long-acting beta(2)-agonist alone for chronic obstructive pulmonary disease [review]. Cochrane Database Syst Rev. 2012;4:CD008989.

3. Mahler DA, D'Urzo A, Bateman ED, et al; INTRUST-1 and INTRUST-2 study investigators. Concurrent use of indacaterol plus tiotropium in patients with COPD provides superior bronchodilation compared with tiotropium alone: a randomised, double-blind comparison. Thorax. 2012;67(9):781-788.

4. Rabe KF, Timmer W, Sagkriotis A, Viel K. Comparison of a combination of tiotropium plus formoterol to salmeterol plus fluticasone in moderate COPD. Chest. 2008;134(2):255-262.

5. Tashkin DP, Celli BR, Decramer M, Lystig T, Liu D, Kesten S. Efficacy of tiotropium in COPD patients with $\mathrm{FEV}_{1} \geq 60 \%$ participating in the UPLIFT $^{\circledR}$ trial. COPD. 2012;9(3):289-296.

6. van Noord JA, Aumann JL, Janssens E, et al. Comparison of tiotropium once daily, formoterol twice daily and both combined once daily in patients with COPD. Eur Respir J. 2005;26(2):214-222.

7. van Noord JA, Aumann JL, Janssens E, et al. Effects of tiotropium with and without formoterol on airflow obstruction and resting hyperinflation in patients with COPD. Chest. 2006;129(3):509-517.

8. van Noord JA, Buhl R, Laforce C, et al. QVA149 demonstrates superior bronchodilation compared with indacaterol or placebo in patients with chronic obstructive pulmonary disease. Thorax. 2010;65(12): 1086-1091.

9. Szmidt M. The influence of treatment with formoterol, formoterol with tiotropium, formoterol with inhaled glucocorticosteroid and tiotropium on lung functions, tolerance of exercise and simple, morning everyday activities in patients with chronic obstructive pulmonary disease (COPD). Pneumonol Alergol Pol. 2012;80(3):255-262. Polish [with English abstract].

10. Yu AP, Guérin A, Ponce de Leon D, et al. Therapy persistence and adherence in patients with chronic obstructive pulmonary disease: multiple versus single long-acting maintenance inhalers. J Med Econ. 2011;14(4):486-496.

11. Beeh KM, Singh D, Di Scala L, Drollmann A. Once-daily NVA237 improves exercise tolerance from the first dose in patients with COPD: the GLOW3 trial. Int J Chron Obstruct Pulmon Dis. 2012;7: 503-513.

12. D'Urzo A, Ferguson GT, van Noord JA, et al. Efficacy and safety of once-daily NVA237 in patients with moderate-to-severe COPD: the GLOW1 trial. Respir Res. 2011;12:156.

13. Dahl R, Chung KF, Buhl R, et al; INVOLVE (INdacaterol: Value in COPD: Longer Term Validation of Efficacy and Safety) Study Investigators. Efficacy of a new once-daily long-acting inhaled beta2agonist indacaterol versus twice-daily formoterol in COPD. Thorax. 2010;65: 473-479.

14. Feldman G, Siler T, Prasad N, et al; INLIGHT 1 study group. Efficacy and safety of indacaterol 150 microg once-daily in COPD: a doubleblind, randomised, 12-week study. BMC Pulm Med. 2010;10:11. 
15. Kerwin E, Hébert J, Gallagher N, et al. Efficacy and safety of NVA237 versus placebo and tiotropium in patients with COPD: the GLOW2 study. Eur Respir J. 2012;40(5):1106-1114.

16. Kornmann O, Dahl R, Centanni S, et al; INLIGHT-2 (Indacaterol Efficacy Evaluation Using 150- $\mu$ g Doses with COPD Patients) study investigators. Once-daily indacaterol versus twice-daily salmeterol for COPD: a placebo-controlled comparison. Eur Respir J. 2011;37(2): 273-279.

17. Bateman ED, Ferguson GT, Barnes N, et al. Dual bronchodilation with QVA149 versus single bronchodilator therapy: the SHINE study. Eur Respir J. Epub 2013 May 30.

18. Dahl R, Chapman KR, Rudolf M, et al. Safety and efficacy of dual bronchodilation with QVA149 in COPD patients: the ENLIGHTEN study. Respir Med. 2013;107(10):1558-1567.

19. Vogelmeier CF, Bateman ED, Pallante J, et al. Efficacy and safety of once-daily QVA149 compared with twice-daily salmeterol - fluticasone in patients with chronic obstructive pulmonary disease (ILLUMINATE): a randomised, double-blind, parallel group study. Lancet Resp Med. 2013;1(1):51-60.

20. Wedzicha JA, Decramer.M, Ficker JH, Sandstorm T, Taylor AF. Dual bronchodilator treatment for the prevention of exacerbations of chronic obstructive pulmonary disease: the SPARK Study. Lancet Resp Med. 2013;1:199-209.

21. Mahler DA, Decramer M, D’Urzo A, et al. Superior lung function with once-daily QVA149 translates into improvements in patient-reported breathlessness compared with placebo and tiotropium in COPD patients: the BLAZE study. Am J Respir Crit Care Med. 2013;187:A6070.

22. Novartis Pharmaceuticals. Comparison of safety and efficacy of the combination product QVA149 A against the concurrent administration of the individual components, QAB149 and NVA237, in patients with chronic obstructive pulmonary disease (COPD) (BEACON). Available from: http:/clinicaltrials.gov/ct2/show/NCT01529632. NLM identifier: NCT01529632. Accessed August 23, 2013.
23. Novartis Pharmaceuticals. Efficacy and safety of QVA149 in patients with chronic obstructive pulmonary disease (COPD). Available from: http://www.clinicaltrials.gov/ct2/show/NCT00570778?term=NCT0057 0778\&rank=1. NLM identifier: NCT00570778. Accessed February 25, 2013.

24. Cazzola M, Tashkin DP. Combination of formoterol and tiotropium in the treatment of COPD: effects on lung function. COPD. 2009;6(5):404-415.

25. Berton DC, Reis M, Siqueira AC, et al. Effects of tiotropium and formoterol on dynamic hyperinflation and exercise endurance in COPD. Respir Med. 2010;104(9):1288-1296.

26. Jones PW, Donohue JF, Nedelman J, Pascoe S, Pinault G, Lassen C. Correlating changes in lung function with patient outcomes in chronic obstructive pulmonary disease: a pooled analysis. Respir Res. 2011; $12: 161$.

27. Antón E. How and when to use inhaled corticosteroids in chronic obstructive pulmonary disease? Expert Rev Respir Med. 2013; 7(Suppl 2):25-32.

28. Van de Maele B, Fabbri LM, Martin C, Horton R, Dolker M, Overend T. Cardiovascular safety of QVA149, a combination of Indacaterol and NVA237, in COPD patients. COPD. 2010;7(6):418-427.

29. Carreiro A, Santos J, Rodrigues F. Impact of comorbidities in pulmonary rehabilitation outcomes in patients with chronic obstructive pulmonary disease. Rev Port Pneumol. 2013;19(3):106-113. Portuguese [with English abstract].
International Journal of COPD

\section{Publish your work in this journal}

The International Journal of COPD is an international, peer-reviewed journal of therapeutics and pharmacology focusing on concise rapid reporting of clinical studies and reviews in COPD. Special focus is given to the pathophysiological processes underlying the disease, intervention programs, patient focused education, and self management protocols.

\section{Dovepress}

This journal is indexed on PubMed Central, MedLine and CAS. The manuscript management system is completely online and includes a very quick and fair peer-review system, which is all easy to use. Visit $\mathrm{http}: / /$ www.dovepress.com/testimonials.php to read real quotes from published authors. 